\title{
The Durability of Cementitious Composites Containing Microencapsulated Phase Change Materials
}

\author{
Zhenhua Wei $\left({ }^{1}\right)$, Gabriel Falzone $\left({ }^{1}\right)$, Bu Wang $\left({ }^{1}\right)$, Alexander Thiele $\left({ }^{2}\right)$, Guillermo Puerta-Falla $\left({ }^{1}\right)$, \\ Laurent Pilon ( $\left.{ }^{2}\right)$, Narayanan Neithalath $\left(^{3}\right)$, Gaurav Sant $\left({ }^{1},{ }^{4},{ }^{*}\right)$
}

\begin{abstract}
This study investigates the durability of cementitious composites containing microencapsulated phase change materials (PCMs). First, the stability of the PCM's enthalpy of phase change was examined. A reductionof around $25 \%$ in the phase change enthalpy was observed, irrespective of PCM dosage and aging. Significantly, this reduction in enthalpy was not caused by mechanical damage that was induced during mixing, but rather by chemical interactions with dissolved $\mathrm{SO}_{4}{ }^{2-}$ ions. Second, the influence of PCM additions on water absorption and drying shrinkage of PCM-mortar composites were examined. PCM microcapsules reduced the rate and extent of water sorption; the former was due to their non-sorptive nature which induces hindrances in moisture movement, and the latter was due to dilution, i.e., a reduction in the volume of sorptive cement paste. On the other hand, PCM inclusions did not influence the drying shrinkage of cementitious composites, due to their inability to restrain the shrinkage of the cement paste. The results suggest that PCMs exert no detrimental influences on, and, in specific cases, may even slightly improve the durability behavior of cementitious composites.
\end{abstract}

Keywords:phase change materials; cement paste;concrete; durability; enthalpy

\footnotetext{
${ }^{1}$ Laboratory for the Chemistry of Construction Materials $\left(L C^{2}\right)$, Department of Civil and Environmental Engineering, University of California, Los Angeles, CA 90095, United States

${ }^{2}$ Department of Mechanical and Aerospace Engineering, University of California, Los Angeles, CA 90095, United States

${ }^{3}$ School of Sustainable Engineering and the Built Environment, Arizona State University, Tempe, AZ, 85287, United States

${ }^{4}$ California NanoSystems Institute, University of California, Los Angeles, CA 90095, United States

* Corresponding Author: G. Sant, Phone: (310) 206-3084, Email: gsant@ucla.edu
} 


\section{Introduction and background}

Heating, ventilation, and air conditioning of buildings accounts for nearly $20 \%$ of annual energy consumption in the U.S. [1]. The embedment of phase change materials (PCMs) in building materials is an effective means to reduce such energy expenditures [2-6]. The benefits of energy efficiencyarise from the ability of PCMs to store and release heat in response to temperature changes by undergoing reversible phase transitions between the solid and liquid states. Organic compounds such as paraffins and fatty acids are often used as PCMs due to their low cost, high latent heat of fusion, and appropriate temperature of phase change $\left(T_{p c}\right)[4,6]$. These materials are generally used in microencapsulated forms (with particle diameter of $1 \mu \mathrm{m}-1 \mathrm{~mm}$ ) to facilitate handling and to prevent PCM exposure with caustic building materials [4].

The economic feasibility of employing microencapsulated PCMs in cementitious composites (i.e., PCM-mortar composites) depends on the ability of PCMs to reduce energy expenditures while embedded within a structural material [7]. Therefore, the PCM must retain its enthalpy of phase change over the service life of the composite. This requires the following: (i) physical durability of PCM capsules, i.e., the ability to resist rupture during concrete mixing and during thermal cycling, and (ii) chemical stability of the PCM microcapsules within the alkaline cementitious environment [8-10]. Moreover, the dosage of the PCMs should not detrimentally influence the durability of the cementitious matrix in which they are embedded.

Numerous studies have examined the ability of PCMs to reduce energy needs that are associated with heating/cooling buildings $[2-6,11]$. A smaller body of researchhas examined the ability of PCMs to mitigate early-age temperature rise in cementitious materials caused by exothermic cement hydration, and the resultant risk of thermal cracking [12-14]. In spite of extensive efforts, only a few studies have examined the durability of PCMs in the context of their chemical durability in alkaline cementitious environments [12, 15]. During hydration, cement particles dissolve, turning the pore solution into a caustic electrolyte [16]. The pore solution contains alkalis, $\mathrm{SO}_{4}{ }^{2-}$, and $\mathrm{Ca}^{2+}$ species, presenting a $\mathrm{pH}$ typically greater than 13 [1719]. When microencapsulated PCMs are embedded in such caustic systems, chemical reactions between the pore solution and the capsule shell could result in damaging alterations, which could reduce the enthalpy of phase change [12]. Thus, it is of great importance to investigate the extent to which exposure to caustic cementitious environments affects microencapsulated PCMs' thermal storage capability. With these considerations in mind, the present study systematically examines:

- PCM survivability during fabrication of PCM-mortar composites, with respect to damage and/or rupture of the PCM microcapsules that may occur during mechanical mixing,

- Chemical durability of PCM within cementitious matrices, and the potential interactions between the PCM and the pore-fluid that result in enthalpy alteration (reduction), and

- Cementitious matrix durability, with emphasis on assessing how dosage of PCMs alters water absorption anddrying shrinkage behavior of cementitious composites containing PCMs. 
is carried out or not. This observed enthalpy reduction is attributed to chemical reaction of the PCM shell material with sulfate ions, causing the release of core material, and its reaction with the pore solution. To the best of our knowledge, this is the first time that a reduction in enthalpy of phase change of PCMs in cementitious environments and its mechanism have been reported. Additionally, we observe that PCMs only minimally influence the drying shrinkage of PCM-mortar composites, while beneficially reducing water sorption similar to other nonsorptive inclusions. These latter parameters which reflects the tightness of concrete to aggressive agents [20-25] and its resistance to cracking, respectively, are critical indicators of concrete durability [26-29].

\section{Materials and Methods}

\subsection{Materials}

Four different commercially available microencapsulated PCMs were used: MPCM6D, MPCM24D, MPCM43D (Microtek Laboratories) and Micronal DS 5008X (BASF Corporation). The relevant onsetmelting temperatures (indicative of $\mathrm{T}_{\mathrm{pc}}$ ) were $4.1{ }^{\circ} \mathrm{C}, 19.6^{\circ} \mathrm{C}, 41.2^{\circ} \mathrm{C}$, and $22.8^{\circ} \mathrm{C}$, respectively, as measured by differential scanning calorimetry (DSC).The Microtek PCMs consisted of paraffin (alkane) cores that are encapsulated within melamine-formaldehyde (MF) shells, while the BASF PCM consisted of a paraffin/alkane core that was encapsulated within an acrylate polymer shell. In each case, variations in the phase change temperature are realized by altering the "chain length", i.e., the number of carbon atoms in an alkane of generic composition $\left(\mathrm{C}_{n} \mathrm{H}_{2 n+2}\right.$, where ' $\mathrm{n}$ ' is the number of carbon atoms). The PCMs werereceived in the form of dry powders.

These fourmicroencapsulated PCMs were selected for study since they encompass the range of phase change temperatures relevant for use in cementitious composites. Specifically, $T_{p c}$ near $0^{\circ} \mathrm{C}$ (e.g., MPCM6D) may be beneficial to mitigate freeze-thaw damage [30], $T_{p c}$ close to room temperature (e.g., MPCM24D and Micronal DS 5008X) may be beneficial in reducing HVACrelated energy expenditures [6], and a higher $\mathrm{T}_{\mathrm{pc}}$ (e.g., MPCM43D) may be used to mitigateearly-age temperature rise caused by (exothermic)cement hydration [12]. Each of the microencapsulated PCMs has been characterized in detail, e.g., in terms of: (i) their particle size distributions using static light scattering, (ii) their surface morphology using scanning electron microscopy (SEM), and (iii) their enthalpy of phase change using DSC; before and after immersion in alkaline solutions.

To more comprehensively assess chemical stability, MPCM24D was also immersed in sulfate-rich solutions, and examined morphologically using SEM and for compositional changes using X-ray diffraction (XRD). Further, MPCM24D-mortar composites were examinedin terms of both their drying shrinkage and water sorption behavior. Broadly, all other PCMs are expected to show similar behavior as MPCM24D based composites due to their similar shell/alkane-core compositions.

An ASTM C150 [31] compliant Type I/II ordinary Portland cement (OPC) was mixed with deionized (DI) water to prepare cement pastes and mortars in accordance with ASTM C192 [32]. The OPC had a nominal mass-based mineralogical composition of: $56.5 \% \mathrm{Ca}_{3} \mathrm{SiO}_{5}, 18.0 \% \mathrm{Ca}_{2} \mathrm{SiO}_{4}$, 

$\mathrm{CaSO}_{4} \cdot 0.5 \mathrm{H}_{2} \mathrm{O}$, and $0.5 \% \mathrm{CaO}$. An ASTM C778 [33] compliant graded quartz sand (denoted as quartz hereafter) was used as a stiff, non-sorptive aggregate within the cement mortars.

Reference ("control") plain pastes with water-to-cement ratio (w/c, mass basis) of 0.35, 0.45, and 0.55 were prepared for water absorption measurements. For all other tests, cementitious mortars were prepared ata fixed $\mathrm{w} / \mathrm{c}=0.45$ at various dosages of microencapsulated PCM and/or quartz inclusions. The inclusions were dosed as a percentage of the total composite volume at three levels (i.e., 10, 30 and 55 volume \%). These mixturesare denoted by the volume percentage of the type of inclusion present preceded by " $P$ " and/or " $Q$ " corresponding to the PCM and quartz inclusions, respectively. To maintain workability (i.e., to enhance fluidity at high inclusion volume fractions), a commercially available water-reducing admixture (WRA; MasterGlenium 7500, BASF Corporation) was added.The WRA dosage for each mixture was as follows (\% of cement mass): P10 - 0.5\%, P30 - 2.0\%, P20+Q10 - 1.0\%, P10+Q20 - 0.5\%, $P 20+Q 35-1.5 \%, P 10+Q 45-1.0 \%$, and Q55-0.5\%. All other formulations contained no WRA.

\subsection{Experimental methods}

Static Light Scattering: A Beckman Coulter Static Light Scattering (SLS) Particle Analyzer (LS13320) was used to determine the particle size distributions (PSDs) of the OPC, PCM microcapsules, and graded quartz sand used in the specimen preparation, as presented in Figure 1. Each material was first dispersed into primary particles via ultrasonication in isopropanol that also served as the carrier fluid. The densities of OPC, quartz, Micronal DS $5008 \mathrm{X}$ and Microtek microencapsulated PCMs were taken as: $3150 \mathrm{~kg} / \mathrm{m}^{3}, 2650 \mathrm{~kg} / \mathrm{m}^{3}, 300$ $\mathrm{kg} / \mathrm{m}^{3}$, and $900 \mathrm{~kg} / \mathrm{m}^{3}$, respectively. The complex refractive indices of the OPC, PCMs, and quartzwere taken as $1.70+i 0.10$ [34], $1.53+i 0.00$ [35], and $1.54+i 0.00$ [36], respectively. The maximum uncertainty in the PSDs was about $6 \%$ based on 6 replicate measurements.

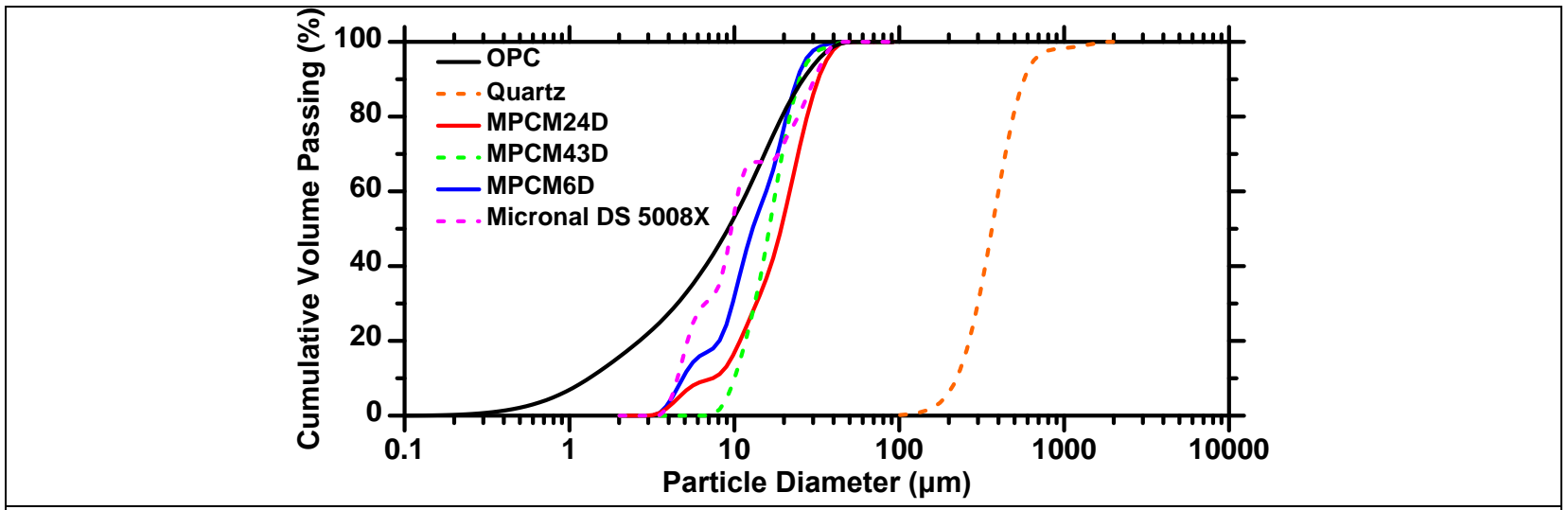

Figure 1: Particle size distributions of OPC, quartz, and the differentmicroencapsulated PCMs measured using static light scattering (SLS).

142 Differential Scanning Calorimetry: The enthalpy of phase change $\left(\Delta \mathrm{H}_{\mathrm{PC}}\right)$, and the phase change 143 temperature $\left(T_{P C}\right)$ of the PCMs was determined by differential scanning calorimetry (DSC 8500, 144 Perkin Elmer)in accordance with ASTM E1269 [37]. Prior tomeasurement, temperature and heat 145 flow calibrations were performed using indium and zinc standards. Samples consisting of $\approx 10$ 
mg of microencapsulated PCMs or PCM-mortar composites were placed in sealed aluminum pans and subjected to a temperature cycle ranging from -50 -to- $100^{\circ} \mathrm{C}$ at a scan rate of $10^{\circ} \mathrm{C} / \mathrm{min}$. The data reported is the average of three replicate specimens.

X-Ray Diffraction: Qualitative X-ray diffraction analysis was performed on PCM microcapsules

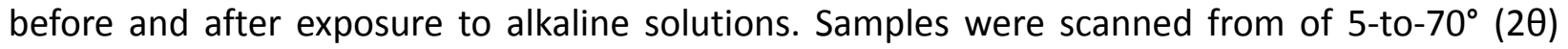
using a Bruker-D8 Advance diffractometer in a $\theta-\theta$ configuration with $\mathrm{Cu}-\mathrm{K} \alpha$ radiation $(\lambda=1.54 \AA$ ) and a VANTEC-1 detector. The diffractometer was run in continuous mode with an integrated step scan of $0.021^{\circ}(2 \theta)$. A fixed divergence slit of $1.00^{\circ}$ was used during X-ray data acquisition.

Scanning Electron Microscopy: SEM observations were performed on pristine PCMs and on PCM capsules before and after immersion in alkaline solutions for 6 hours. The microencapsulated PCMs were deposited on carbon adhesive and then gold-coated. Secondary electron (SE) images were obtained with an accelerating voltage of $10 \mathrm{kV}$ and a beam current of 80 pA using an FEI Nova NanoSEM 230.

Water Absorption: A modified ASTM C1585 [38] procedure was used to characterize the rate and extent of water sorption in PCM-mortar composites. Cylindrical specimens $(d \times h, 10 \mathrm{~cm} \times 20$ $\mathrm{cm}$ ) were cast, then cured for 28 days in saturated limewater before being cut into $10 \mathrm{~cm} \times 3.75$ $\mathrm{cm}$ sections using a diamond-tipped masonry saw. The cylindrical slices wereconditioned at $50{ }^{\circ} \mathrm{C}$ in a desiccator at relative humidity $(\mathrm{RH})$ of $80 \%$ established using a saturated $\mathrm{KBr}$ solutionfor 3 days. Thereafter, each sample was stored in a sealed container for another 15 days to allow moisture redistribution. The sides and one face of the cylinder were sealed with aluminum tape, leaving only one open face exposed to water at $23^{\circ} \mathrm{C}$. The mass of water absorbedthrough this face was recorded over a time period of 8 days using a laboratory balance (ML1502E, Mettler Toledo) with a precision of $\pm 0.01 \mathrm{~g}$. The data reported is the averageof three replicate specimens prepared from the same mixing batch.

Drying Shrinkage: Unrestrained drying deformations of cementitious specimens were measured as per ASTM C157 [39]. Cement pastes and mortars were cast in prismatic molds $(2.5 \mathrm{~cm} \times 2.5$ $\mathrm{cm} \times 28.5 \mathrm{~cm}, w \times h \times l)$, cured for 24 hours above water in a sealed container, prior to curing in saturated limewater until an age of 28 days. The specimens were subsequently dried, sealed on two sides with aluminum tape to ensure 1D moisture diffusion, and stored at $25.0 \pm 0.2^{\circ} \mathrm{C}$ and $50.0 \pm 0.2 \% \mathrm{RH}$ in an environmental chamber (KB024-DA, Darwin Chambers Company). Changes in the prismatic samples' lengths were recorded at $1,3,7,14,28,56$, and 90 days from the start of the drying period. The data reported is the average of four replicate specimens prepared from the same mixing batch.

\section{Results and Discussion}

\subsection{Stability of the PCM's phase change enthalpy in cementitious environments}

Figure 2(a) displays DSC heat flow curves showingthe melting and solidification behavior of pristine MPCM24D microcapsules. The curves show small peaks attributed to impurities blended into the paraffin (the active PCM ingredient) to control its phase change temperature [40]. The peak temperature during the melting (heating) process was about $27.8^{\circ} \mathrm{C}$, while the 
peak temperature during the solidification (cooling) was about $16.6^{\circ} \mathrm{C}$. The difference between observed peak temperatures for melting and solidification is indicative of supercooling, which is common in microencapsulated PCMs, due to the lack of heterogeneous nucleation sites for solidification to initiate within the microcapsules [4-6]. The enthalpies of phase change were $161.2 \pm 0.5 \mathrm{~kJ} / \mathrm{kg}$ and $136.6 \pm 0.4 \mathrm{~kJ} / \mathrm{kg}$ for pristine MPCM24D and Micronal DS 5008X, respectively (for other PCMs, see Supplementary Materials, Section S.1). The data reported is the average of three replicates.

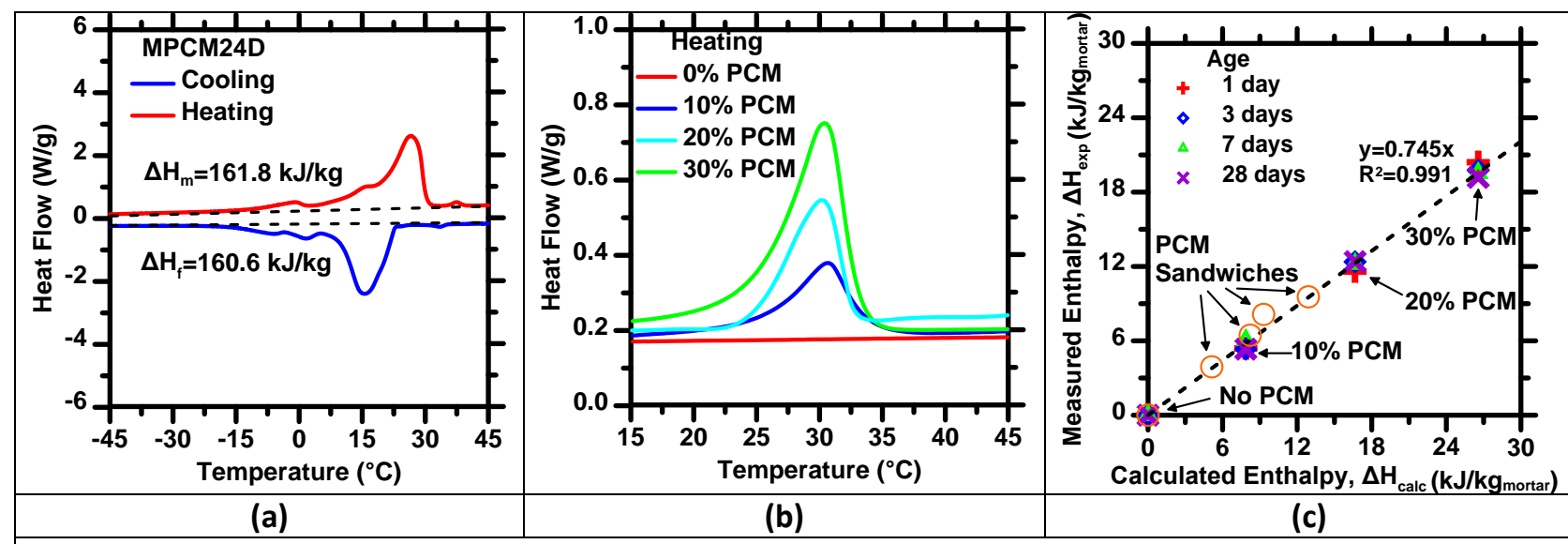

Figure 2:(a) Representative DSC curves illustrating the enthalpy of melting and solidification of pristine MPCM24D. (b) Representative DSC curves for a PCM-mortar composites (w/c $=0.45$ ) containing different volume fractions of MPCM24D.For clarity, only the endothermic (melting) peaks are shown, as the enthalpy of phase change measured during solidification is similar to that observed during melting.(c) Themeasured enthalpyof phase change for PCM-mortar composites $(w / c=0.45)$ as a function of the enthalpy that is expected based on the mass dosage of PCM in the composite (Equation 1). Evenwhen mechanical mixing is avoided (e.g., see data for PCM "sandwiches"), anenthalpy reduction is noted, indicating that mixing and mechanical damage caused to the PCM capsules is not the cause of enthalpy reduction.

198

Figure 2(b) shows DSC heating curves for cement mortar specimens containing 0, 10, 20 and 30 volume \% MPCM24D in the mixture. The temperature corresponding to the onset $\left(24 \pm 1^{\circ} \mathrm{C}\right)$ of phase change, and the temperature at the peak $\left(27 \pm 1^{\circ} \mathrm{C}\right)$ were similar regardless of the PCM dosage. No peaks were observed in the DSC curve of the plain cement paste, as expected. It is worth pointing out that the cooling curves show behavior similar to that of the heating curves, and the enthalpy of solidification is equal and oppositeto that corresponding to melting. The microencapsulated PCM mass fraction in the composite dictates its "expected" phase change enthalpy $\Delta H_{\text {calc }}$ (in $\mathrm{kJ} / \mathrm{kg}$ ) expressed as,

$$
\Delta H_{\text {calc }}=\frac{m_{P} h_{s f, P}}{m_{P}+m_{m}}
$$

where, $h_{s f, P}$ is the measured latent heat of fusion of the core-shell PCM microcapsules (e.g., $161.2 \mathrm{~kJ} / \mathrm{kg}$ for MPCM24D), while $m_{P}$ and $m_{m}$ are the masses of core-shell PCM microcapsules and the cement paste in the composite, respectively. Figure 2(c) shows the correlation between the measured phase change enthalpy of PCM-containing cementitious composites, $\Delta H_{\exp }$, and that calculated using Equation (1), $\Delta H_{\text {calc }}$. A linear relation is noted between $\Delta H_{\text {exp }}$ and $\Delta H_{\text {calc }}$, but with a slope of 0.75 . As such, the incorporation of PCM microcapsules within the cementitious 
paste results in a $25 \%$ enthalpy reduction, which was observed to be independent of both the PCM dosage and the age of the cementitious composite. A similar enthalpy reduction was observed previously when Micronal DS 5008X PCM microcapsules were added to cement pastes [12].

PCM capsulesurvivability during mechanicalmixing:Mechanical mixing of the PCM-mortar composites, and the potential damage it causes to the PCM microcapsules, was investigated as the cause of the enthalpy reduction observed in Figure 2(c). As a comparison to PCM mortars that were fabricated by mixing the cement, microencapsulated PCM, and water in a planetary action mixer as per ASTM C305 [41], an additional set of PCM-mortar composites was created within a DSC pan $(\phi=5 \mathrm{~mm}$ ) by gently sprinkling onto an underlying paste layer, PCM particles, and then covering these particles with additional cement paste, forming a "sandwich", after which the pan was crimped shut. The resulting PCM sandwich specimens were cured for 3 days in a sealed conditionprior to DSC characterization. This preparation procedure was used to avoid any damage that may be induced on the PCM microcapsules due to shear and frictional forces that may develop duringmechanical mixing. As such, this procedure enables discrimination of the effects of mechanical mixing from those associated with the nature of the chemical environment. Figure 2(c) reveals the measured enthalpy of phase change of these PCM sandwich composites falls on the same trend line as those subjected to mechanical mixing, indicating that mechanical mixing is not the cause of the observed enthalpy reduction. As such, this clarifies that a chemical rather than mechanicalcause is at the origin of the enthalpy reduction observed in PCM containing cementitious composites.

Chemical stability of PCM within model cementitious environments: To evaluate the chemical stability of microencapsulated PCMsin alkaline conditions similar to cement pore solutions, PCM microcapsules were immersed in solutions of the following compositions: $0.02 \mathrm{M} \mathrm{Ca}(\mathrm{OH})_{2}, 0.5$ $\mathrm{M} \mathrm{NaOH}, 1 \mathrm{M} \mathrm{NaOH}, 2 \mathrm{M} \mathrm{NaOH}$, and $3 \mathrm{M} \mathrm{NaOH}$. Following 1, 3, 7, and 28 days of immersion, the enthalpy of phase change and the onset temperature of phase change of the PCM microcapsules were characterized via DSC.

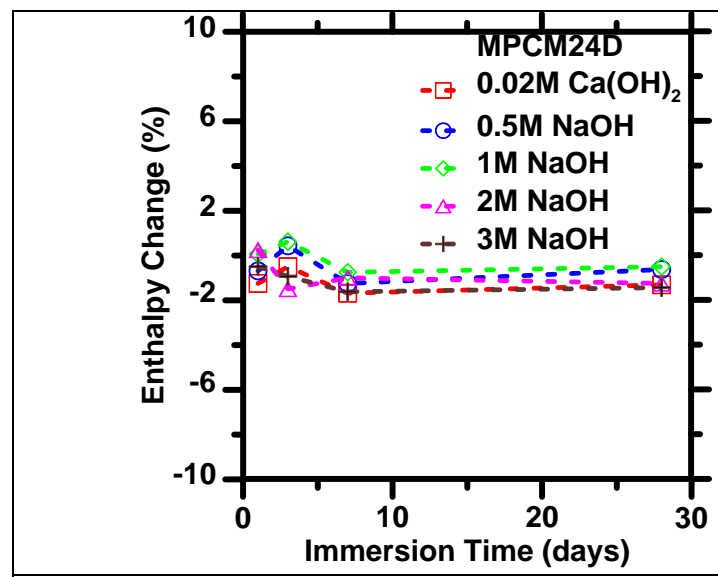

(a)

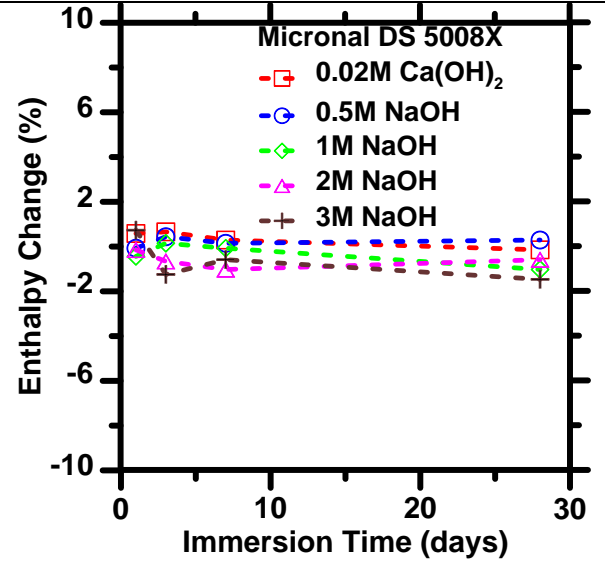

(b)

Figure 3: The relative change in the enthalpy of phase change for (a) MPCM24D, and (b) Micronal DS 5008X following immersion in alkaline (similar to pore fluid) solutions for 28 
243

days. The highest uncertainty in each measured data point is on the order of $\pm 1 \%$.

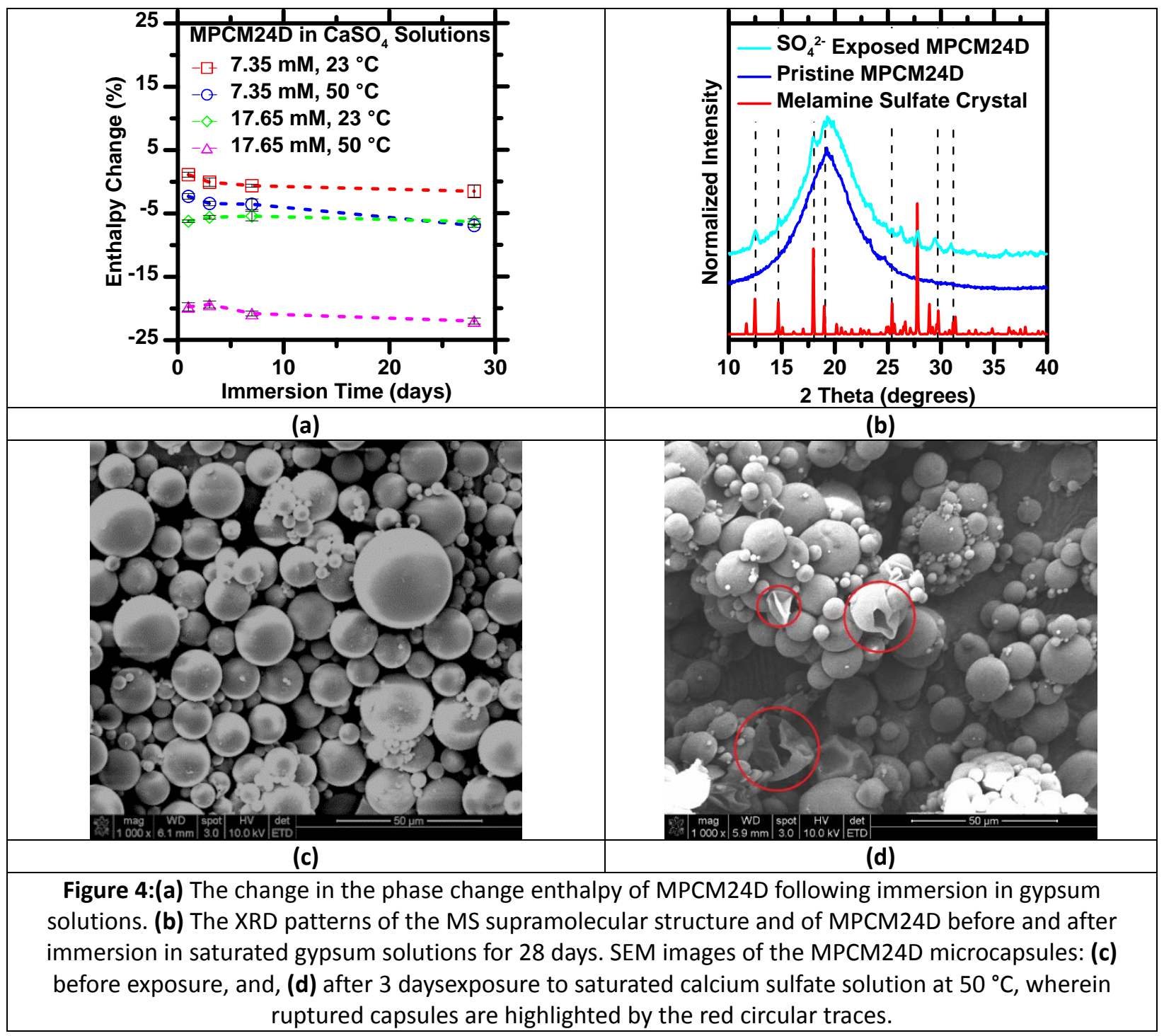

244

245

246

247

248

249

250

251

252

253

254

255

256

Figure 3 shows the change in the enthalpy of phase change of MPCM24D and DS 5008X PCM microcapsules as a function of immersion time, relative to that in their pristine condition. Over 28 days of immersion, the enthalpy of phase change of the microencapsulated PCMs decreased by $\leq 2 \%$. This suggests that the PCM capsule is sufficiently stable in alkaline environments. These results were consistent across PCMs of various transition temperatures (see Supplementary Materials, Section S.1). While these results indicate that negligibleenthalpy reduction occurred in alkaline solutions, regardless of the associated cation, these simplified solutions did not contain the diversity of potentially deleterious ions present in the cement pore solution. For example, gypsum (hydrated calcium sulfate, $\mathrm{CaSO}_{4} \cdot \mathrm{H}_{2} \mathrm{O}$ ) is commonly added to OPC to control the setting time. In this case, sulfate ions in the pore solution of cement paste may play an important role in deteriorating the PCM microcapsules' shell material, which requires further examination [42].It should be noted that cement pore solution achieves 
gypsum saturation within the first few hours, and the concentration of sulfate ions progressively decreases in time [42].

Figure 4(a) shows the relative change in enthalpy of phase change for MPCM24D microcapsules exposed to $\mathrm{CaSO}_{4} .2 \mathrm{H}_{2} \mathrm{O}$ (gypsum) solutions having concentrations of $7.35 \mathrm{mM}$, and $17.65 \mathrm{mM}$, for up to 28 days at $23^{\circ} \mathrm{C}$ and $50^{\circ} \mathrm{C}$. The higher concentration, $17.65 \mathrm{mMcorresponds}$ to the solubility limit of gypsum in water at $23^{\circ} \mathrm{C}$. Also, while the lower temperature corresponds to ambient conditions, the higher temperature $\left(50^{\circ} \mathrm{C}\right)$ corresponds to that which may be achieved in modestly sized concrete sections due to the effects of self-insulation and the exothermic nature of cement + water reactions.

An immediate decrease in the PCM's enthalpy of phase change was observed (i.e., in $\leq 24$ hours) upon immersion in sulfate solutions, especially at slightly elevated temperature. For example, the enthalpy reduction of MPCM24D immersed in saturated calcium sulfate solution at $50^{\circ} \mathrm{C}$ after 28 days was around $23 \%$. These findings suggested that $\mathrm{SO}_{4}{ }^{2-}$ ions play a significant role in inducing the observed $25 \%$ enthalpy reduction following embedment of PCM in cementitious composites (e.g., see Figure 2c). This is attributed to the fact that the shell material of the microencapsulated PCMs was a melamine-formaldehyde (MF) resin that is synthesized by crosslinking melamine with formaldehyde under alkaline conditions. Since the crosslinking reactions are reversible, the crosslinks in MF's structure may breakdown in aqueous environments[43]. Following reversible breakdown, melamineco-crystallizes with $\mathrm{SO}_{4}{ }^{2-}$ ions to form a melamine-sulfate (MS)-like supramolecular structure of molecular formula: $\left[\left(\mathrm{C}_{3} \mathrm{H}_{7} \mathrm{~N}_{6}{ }^{+}\right)_{2}\left(\mathrm{SO}_{4}{ }^{2-}\right)\right] \cdot 2 \mathrm{H}_{2} \mathrm{O}[44]$. It is worth pointing out that the observed PCM enthalpy reduction occurred immediately after exposure to $\mathrm{SO}_{4}{ }^{2-}$ ions - but after this initial reduction, no further change in the enthalpy of phase change was observed.

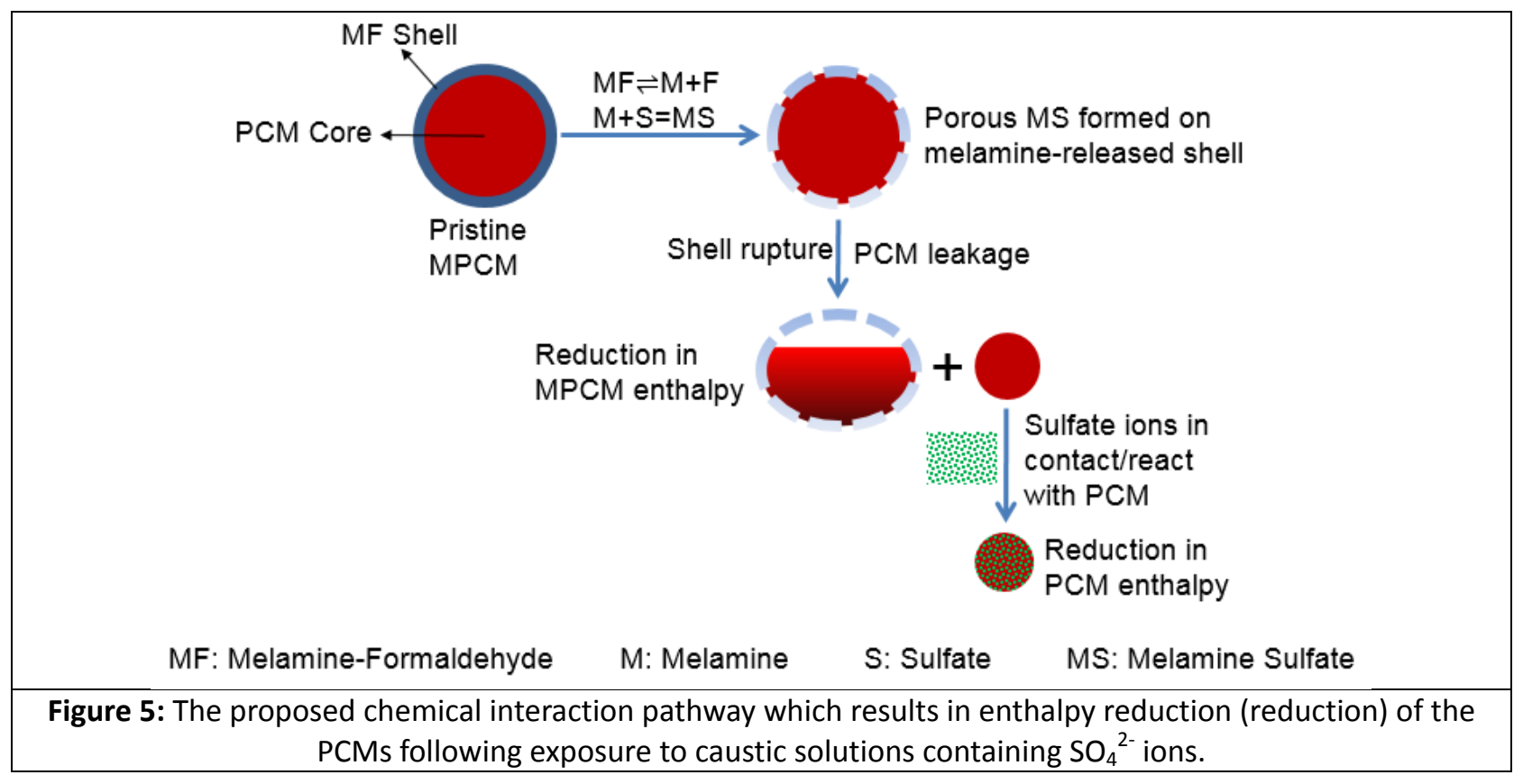


Figure 4(b) shows XRDof MPCM24D samples before and following their immersion in saturated gypsum solutions for 28 days,and those for the melamine-sulfate (MS) supramolecular structure[44]. The X-ray patterns confirm the presence of supramolecular crystal compounds following immersion of PCM microcapsules in a saturated sulfate solution. It is postulated that hydrolysis of the MF crosslinks occurs within the shell of PCM microcapsules exposed to sulfate solutions. This process releases melamine, which then reacts with sulfate ions in solution to form the MS supramolecule with a 3D microporous structure that is linked by intermolecular hydrogen-bonds and aromatic $\pi-\pi$ interactions [44]. These reactions deform and degrade the PCM's shell causing its rupture; after which the paraffinic core contacts the alkaline cementitious pore-fluid. This is confirmed by the SEM images presented in Figures 4(c-d) which show capsule rupture following exposure to gypsum solutions. The reduction in the enthalpy of phase change is thus attributed to the contact of the PCM core material with the high $\mathrm{pH}$ cementitious environment. To confirm this hypothesis, the paraffinic core material of MPCM24Dwas directly dispersed into gypsum solutions and stirred at $50{ }^{\circ} \mathrm{C}$ over a 28 -day exposure period. Before exposure, the enthalpy of phase change of MPCM24D's core material was $199.8 \mathrm{~kJ} / \mathrm{kg}$; which indicated that following its encapsulation, the core accounted for 81 mass \% of the MPCM24Dmicrocapsules. Upon exposure to saturated gypsum solutions, the enthalpy of phase change of the core material decreased to $166.1 \mathrm{~kJ} / \mathrm{kg}$, a $17 \%$ reduction. Since the MF shell has no latent heat capacity, and the enthalpy reduction of MPCM24D immersed in at $50^{\circ} \mathrm{C}$ after 28 days was $\approx 23 \%$ (e.g., see Figure 4 a), it wasestimated that around $30 \%$ of the core material has been released (degraded) from the capsules.These results indicate that chemical reactions between the $\mathrm{PCM}$ core and $\mathrm{SO}_{4}{ }^{2-}$ are primarily responsible for the observed enthalpy reduction (Figure 2c). This pathway of the PCM's enthalpy reduction resulting from chemical interactions is summarized in Figure 5.

\subsection{Moisture transport behavior of PCM-containing cementitious composites}

The water absorption response of PCM-mortars was quantified as per ASTM C1585. This involved measuring incremental mass change (increase) of the samples after $1 \mathrm{~min}, 5 \mathrm{~min}, 10$ $\mathrm{min}, 20 \mathrm{~min}, 30 \mathrm{~min}, 60 \mathrm{~min}, 120 \mathrm{~min}, 180 \mathrm{~min}, 240 \mathrm{~min}, 300 \mathrm{~min}, 360 \mathrm{~min}$, and then every day for up to8 days following their contact with water. The origin of time was taken at the moment when the specimen was first placed in contact with water.The cumulative volume of absorbed water per unit area of inflow surface /(inmm), was calculated as,

$$
I=\frac{\Delta m_{t}}{\rho_{w} A}
$$

316

where $\Delta m_{t}(\mathrm{~g})$ is the cumulative change in specimen mass at time $t$ (seconds), $A\left(\mathrm{~mm}^{2}\right)$ is the area of the specimen exposed to water, and $\rho_{w}$ is the density of water $\left(0.001 \mathrm{~g} / \mathrm{mm}^{3}\right.$ at $\left.23^{\circ} \mathrm{C}\right)$. As per Hall[45], single-phase flow by capillary sorption in an unsaturated porous media can be expressed in the form of a diffusion equation - thus, from theory, I scales to $t^{1 / 2}$. But, in practice a finite positive intercept, $k(\mathrm{~mm})$, is noted as a result of the filling of surface porosity on the inflow surface[45]. As such, the sorptivity $S$ can be determined from the slope of the best-fit line[38],

$$
I=k+S t^{1 / 2}
$$

where $S$ is the sorptivity of the material, i.e., the rate of absorption (in $\mathrm{mm} / \mathrm{h}^{1 / 2}$ ) andt is the time 
(in h). As per ASTM C1585, Equation (3) was fitted to the measured absorption data $I(t)$ within the first 6 hours, and between 1 and 8 days, to calculate the initial sorptivity $\left(S_{1}, \mathrm{in} \mathrm{mm} / \mathrm{h}^{1 / 2}\right)$ and secondary sorptivity $\left(S_{2}\right.$, in $\left.\mathrm{mm} / \mathrm{h}^{1 / 2}\right)$, respectively.

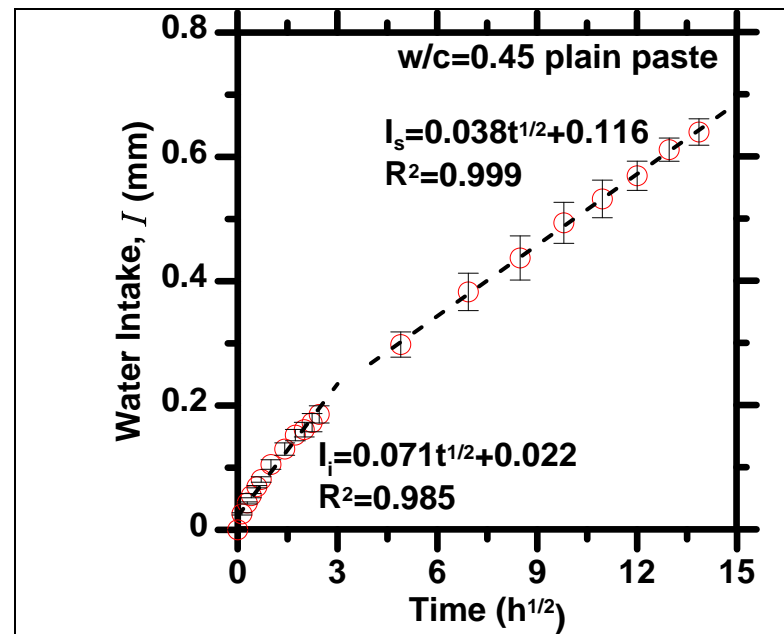

(a)

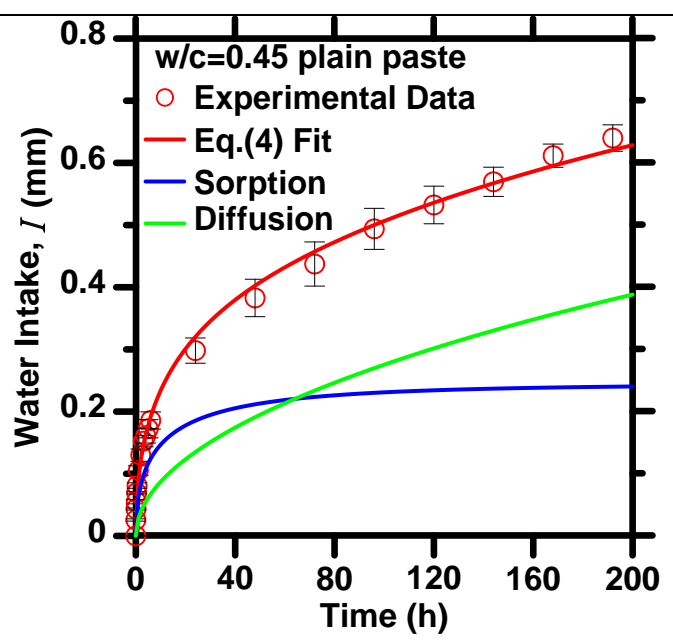

(b)

Figure 6: (a) Water sorption as a function of the square root of time $\left(\mathrm{h}^{1 / 2}\right)$ for a plain cement $(w / c=0.45)$, and (b) Representative fits of the sorption-diffusion equation (Eq. 4 ) to the plain cement paste's water sorption response.

Figure $6(a)$ showsrepresentative water absorption data for a plain cement paste $(w / c=0.45)[38$, 46]. Neithalath [47] proposed that water sorption data can be described by a combination of an exponential term for sorption and a solution of Fick's second law for diffusion to predict timedependent moisture ingress such that,

$$
I=\frac{\Delta m_{t}}{\rho_{w} A}=B\left[1-\exp \left(\frac{-S_{1} t^{1 / 2}}{B}\right)\right]+\frac{C_{0} L}{\rho_{w}}\left\{1-\sum_{n=0}^{\infty} \frac{8}{(2 n+1)^{2} \pi^{2}} \exp \left[\frac{-D_{m}(2 n+1)^{2} \pi^{2} t}{4 L^{2}}\right]\right\}
$$

where $B$ describes thepenetration depth when capillary pores dominateinitial sorption $(\mathrm{mm})$, $C_{0}$ is the concentration of moisture at the specimen's surface $\left(\mathrm{kg} / \mathrm{m}^{3}\right), D_{m}$ is the moisture diffusion coefficient $\left(\mathrm{m}^{2} / \mathrm{h}\right)$, and $L$ is the length of the specimen $(\mathrm{m})$. Experimental data of $I$ estimated using Equation (2), and $S_{1}$ obtained via Equation (3) were used to fit Equation (4), thus revealing the constants $B, C_{0}$, and $D_{m}$. Figure $6(\mathrm{~b})$ displays a representative fit of the Equation (4) for the plain paste $(\mathrm{w} / \mathrm{c}=0.45)$ including the separated contributions of capillary sorption and of diffusion, respectively. As expected, the contribution of capillary sorption to moisture intake was dominant at early times, andvanished over time, while the diffusion term represented long-term moisture transport involving the smaller gel pores [46, 47]. The fitting of Equation (4) to the experimental water intake of the cement mortars (for $w / c=0.45$ ) containing various dosages of PCM's and/or quartz inclusions were determined (see Supplementary Materials, Section S.2). Note that, based on Equation (4), after an infinite amount of time, the cumulative water absorbed in the specimen is equal to $B+C_{0} L / \rho_{w}$. 
Figure $7(a)$ displays the initial $S_{1}$ and secondary $S_{2}$ sorptivities measured for all mixtures (for $\mathrm{w} / \mathrm{c}=0.45$ ) as functions of inclusion volume fraction $\phi_{P+Q}$. It is noted that regardless of the nature of inclusions present (i.e., PCM or quartz), both $S_{1}$ and $S_{2}$ decreased linearly with increasing total inclusion volume fraction. This is because both quartz and PCM serve as non-sorptive inclusions [48]. As the volume fraction of non-sorptive inclusions increases, capillary flow is redirected around inclusion particles, increasing the tortuosity of the transport path. As a result, moisture penetration rates diminish. Further, the initial sorptivity decreased faster than the secondary sorptivity, indicating a greater relative importance of diffusive moisture transport with increasing inclusion dosage. In addition, the effective moisture diffusion coefficient $D_{m}$ (Figure 7b) decreased systematically with inclusion dosage since both PCM and quartz were non-porous inclusions, far less permeable than the cement paste. In turn, the total amount of water absorbed by the composites diminished with inclusion dosage due to the dilution of the content of porous cement paste, which is the main water-sorbing component in the composite (see Figure 7c).

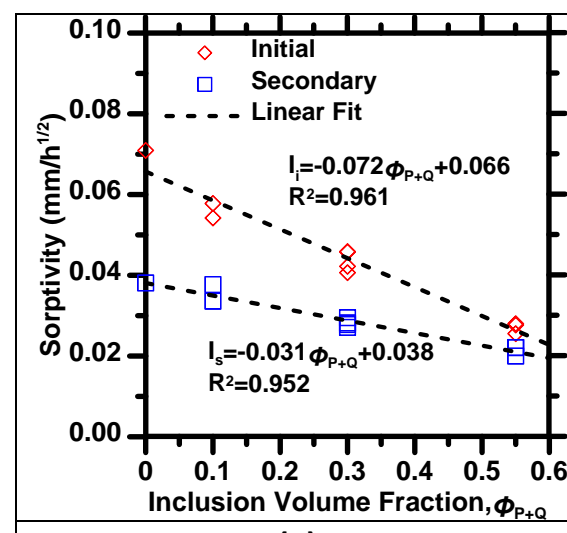

(a)

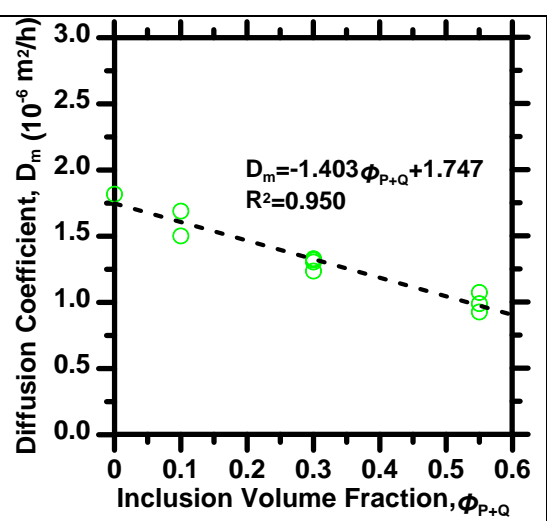

(b)

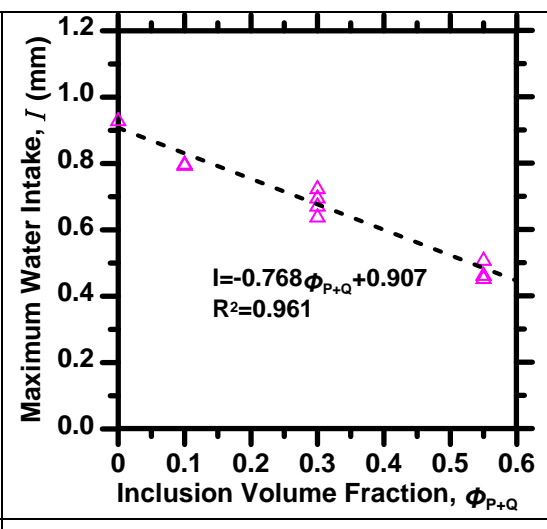

(c)

Figure 7: (a)Water sorptivity, (b)Moisture diffusion coefficients of cementitious composites containing PCM and/or quartz inclusionsfor $w / c=0.45$, and (c) The cumulative amount of water absorbed by cementitious composites containing PCM and/or quartz inclusions for $\mathrm{w} / \mathrm{c}=0.45$ after infinite time.

364

365

366

367

368

369

370

371

372

373

374

375

376

377

378

As water absorption appeared relatively insensitive to the type of inclusion, a model was sought to capture both the effects of $\mathrm{w} / \mathrm{c}$ and inclusion volume (i.e., reduction in paste content) on water absorption. Simply, water absorption depends on the unsaturated and interconnected porosity of the system, i.e., the volume available to be filled with water. The total porosity, composed of capillary porosity $\left(\mathrm{V}_{\mathrm{cw}}\right)$, the gel porosity $\left(\mathrm{V}_{\mathrm{gw}}\right)$, and chemical shrinkage $\left(\mathrm{V}_{\mathrm{cs}}\right)$ in a cement paste can be determined by Powers' model which estimates the volume relationships among constituents and porosity of the mixtures during the hydration process $[49,50]$ at a given degree of cement reaction, here taken to be $80 \%$ after 28 days [51].

Since both PCM and quartz were non-sorptive and non-reactive inclusions, and assuming that no volume expansion occurs during wetting, the total porosity of the mixture can be calculated as a function of $w / c$, degree of reaction ( $\alpha$, unitless), and the inclusion dosage. Indeed, isothermal calorimetry has indicated that PCM microcapsules and quartz inclusions exert no appreciable effect on the degree of hydration[12]. As such, Figure 8 shows the maximum long- 
term water uptake of a range of cementitious composites (i.e., both with, and without inclusions) as a function of their total porosity calculated by Powers model [49]. Across all compositions, an empirical logarithmic expression described the relationshipbetween the maximum water uptake $I_{\max }$ and the total porosity $V_{\text {tot }}(i . e$., the sum of the capillary and gel pores, and void spaces created by chemical shrinkage):

$$
I_{\text {max }}=0.50 \ln V_{\text {tot }}+1.36
$$

To ascertain the predictive power of this approach, water sorption experiments were carried out on three additional mixtures having different $\mathrm{w} / \mathrm{c}$ and volume fractions of PCM and quartz: (i) $\mathrm{w} / \mathrm{c}=0.40$ mortar containing 40 volume $\% \mathrm{PCM}$, (ii) $\mathrm{w} / \mathrm{c}=0.50$ mortarcontaining 25 volume $\%$ PCM and 25 volume \% quartz, and (iii) w/c=0.60mortarcontaining 25 volume \% quartz. The empirical expression shown in Equation (6) was able to robustly capture the terminal amount of water sorbed by these mixtures, simply from knowledge of the mixture proportions, and the degree of reaction (see Figure 8). It should be noted that Equation (6) accounts for differences in porosity (volume fraction) based only on the initial $w / c$ of the cement paste. The addition of non-sorptive inclusions dilutes the volume fraction of the porous cement paste, thereby reducing the volume of porosity in the cementitious composite. Therefore, the present expression only accounts for the effects of non-sorptive (or negligibly sorptive) inclusions. While Equation (6) could indeed be modified to represent the effects of porous aggregates, i.e., by taking aggregate porosity into account in the porosity volume fraction parameter $V_{\text {tot }}$-this approach was not implemented here. As such, it is possible to estimate terminal water sorption from the porosity of the material. Of course, the results indicate that PCMs diminish water sorption similar to other non-porous inclusions, an effect that is casued on account of dilution of the cement paste content.

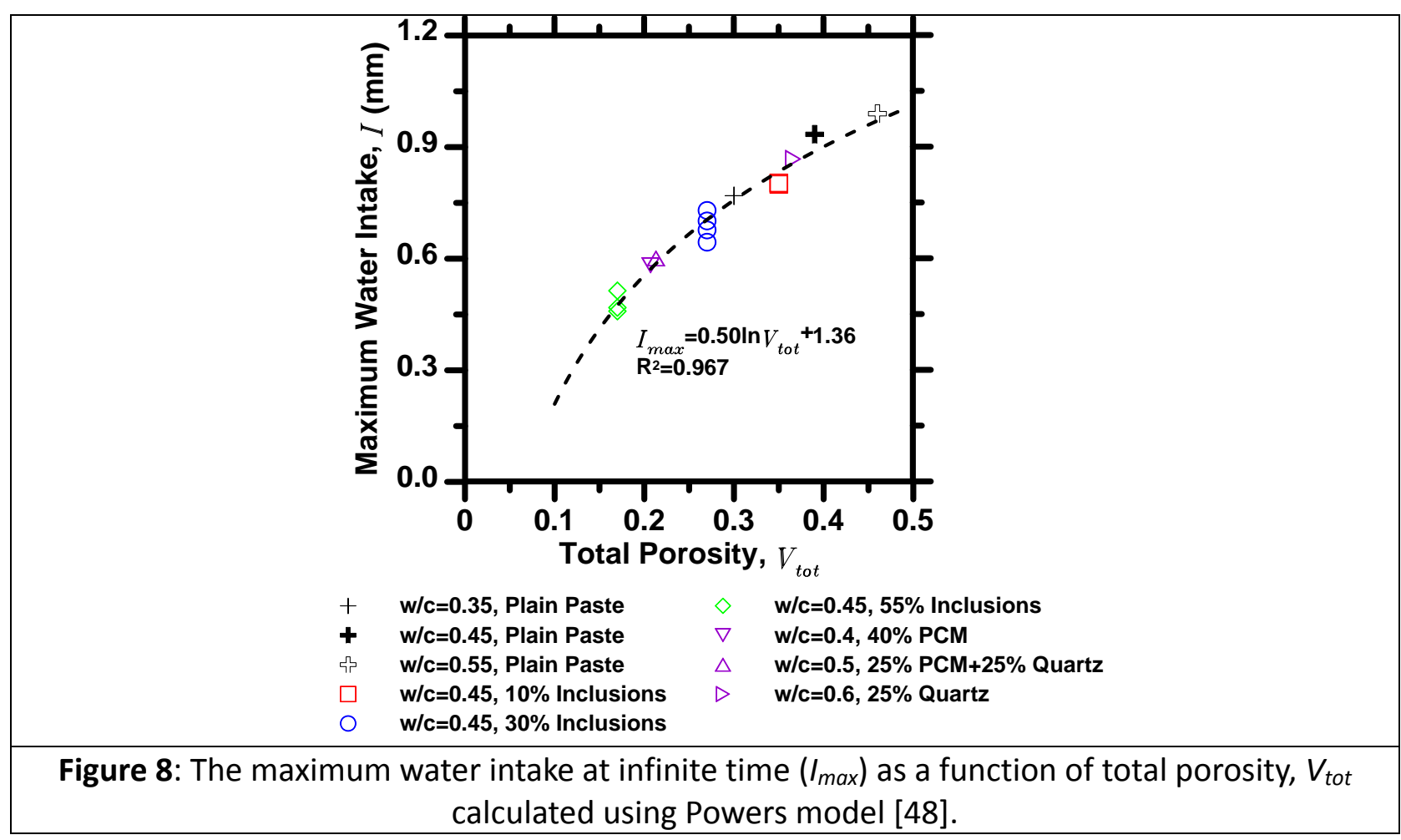




\subsection{Unrestrained drying shrinkage of cementitious composites containing PCMs}

Figure 9 shows the drying shrinkage $\operatorname{strain}(S, \mu \varepsilon)$ of cementitious composites containing PCM and/or quartz inclusions as a function of time, with a fixed $w / c=0.45$. For both quartz mortars and mixed mortars (i.e., those containing both quartz and PCM inclusions), increasing the quartz volume fraction reduced drying shrinkage, since stiff inclusions restrain the shrinkage of the paste [12].The dosage of microencapsulated PCM inclusions resulted in no change in shrinkage, vis-à-vis the plain cement paste. This is because the soft PCM inclusions, due to their compliant nature, are unable to restrain the shrinkage of the cement paste upon drying. This is supported by the observation that, when PCM and quartz inclusions were dosed together, the measured shrinkage response was equal to that expected for a mixture containing only quartz inclusions.

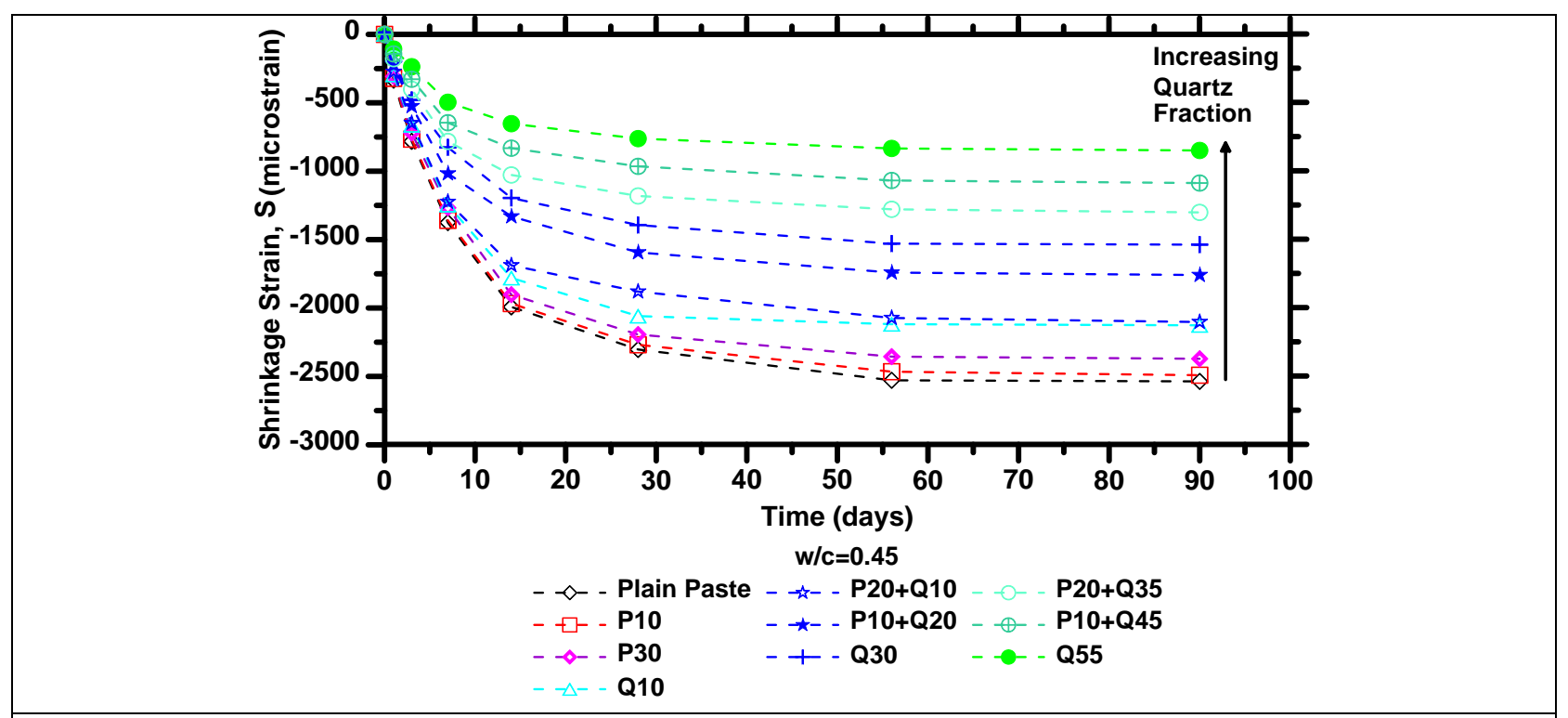

Figure 9: Shrinkage plotted against the drying time for samples containing different volume fractions of PCM and/or quartz.

To better understand the trends in shrinkage, and the influence of the inclusion properties, the model of Hobbs developed for two-component composites (i.e., matrix + inclusion) was applied to predict the shrinkage of the composite[29,52]. This model is expressed as [29],

$$
S_{m+i}=S_{m}-\frac{2 K_{i}\left(S_{m}-S_{i}\right) \phi_{i}}{K_{i}+K_{m}+\left(K_{i}-K_{m}\right) \phi_{i}} \quad \text { with } \quad K_{j}=\frac{E_{j}}{3\left(1-2 v_{j}\right)}
$$

where $S_{j}, K_{j}, E_{j}$, and $u_{j}$ are the shrinkage strain, bulk modulus,modulus of elasticity, and Poisson's ratio of component $j$ of volume fraction $\phi_{j}$, respectively. Here, the subscripts $m+i, m$, and irefer to the two-component composite, the matrix (cement paste), and the inclusions (PCM or quartz), respectively. The shrinkage of PCM microcapsules was assumed to be near-equivalent to that of the cement paste, and quartz was assumed to be non-shrinking[12], Therefore the 
425 shrinkage ratio of quartz and PCM inclusions in relation to cement paste are taken as: $S_{o} / S_{m}=0.01$ and $S_{p} / S_{m}=0.99$. The bulk modulus of the cement paste was calculated: (i) from measured data of its modulus of elasticity $E_{m}=9.58 \mathrm{GPa}, 13.48 \mathrm{GPa}, 15.65 \mathrm{GPa}$, and $16.75 \mathrm{GPa}$ [52] at ages of $1,3,7$, and 28 days, respectively and (ii)assuming its Poisson's ratio to be $u_{m}=0.2$ [53]. The modulus of elasticityand Poisson's ratio of the microencapsulated PCM and quartz inclusions were estimated based on literature data as: $E_{P}=0.0557 \mathrm{GPa}, U_{P}=0.499$ [54], and $E_{Q}=$ $72 \mathrm{GPa}, v_{Q}=0.22$ [55], respectively. The Hobbs model assumesthe following: (i) the cementitious composites consist of only two phases (i.e., inclusion particles dispersed in a continuous cement paste matrix), (ii) the inclusions andcement paste matrix are elastic, and (iii) the elastic properties of the components do not change with shrinkage.

For three-component systems (i.e., PCM microcapsules + quartz + cement paste), a two-step approach was applied to calculate the shrinkage strain via the Hobbs model. In this approach, the PCM and cement paste were treated as a homogeneous matrixinto whichquartz inclusions were embedded. The effective modulus of elasticity of the cement paste embedded with PCMs 441 was computed using Hobbs model (for modulus of elasticity) as[29],

$$
E_{m+P}=\frac{\left(1-2 v_{m+P}\right)\left(1-\frac{\phi_{P}}{1-\phi_{Q}}\right) E_{m}}{\left(1-2 v_{m}\right)\left(1+\frac{\phi_{P}}{1-\phi_{Q}}\right)}
$$

442

443

444

445

446

where $E_{m+p}$ is the effective modulus of elasticityof the paste + PCM composite, and $E_{m}$ and $E_{p}$ are the moduli of elasticity of the cementpaste matrixand microencapsulatedPCM, respectively. The corresponding effective Poisson's ratio of the composite, $v_{m+p}$ was calculated based on the ReussVoigt-Hill average [56]as,

$$
v_{m+P}=\left[\left(v_{P} \frac{\phi_{P}}{1-\phi_{Q}}+v_{m} \frac{\phi_{m}}{1-\phi_{Q}}\right)+\left(\frac{v_{P} v_{m}}{v_{P} \frac{\phi_{m}}{1-\phi_{Q}}+v_{m} \frac{\phi_{P}}{1-\phi_{Q}}}\right)\right] / 2
$$

It should be noted that Hobbs model noted in Equation (8) was derived for a case of considerable mismatch between the Poisson's ratios of the components, and assumed that inclusions had a negligible modulus of elasticity compared to that of the matrix(such that $E_{i} \approx 0$, and $S_{i} / S_{m} \approx 1$ ). As such, instead of homogenizing quartz and cement paste as the matrix, quartz was treated as inclusion and embedded into a matrix composed of PCM microcapsules and cement paste.The effective modulus of elasticity $E_{m+p}$ and Poisson's ratio $u_{m+p}$ of the homogenized $\mathrm{PCM}+$ cement paste composite were used to calculate its effective bulk modulus $\left(K_{m+P}\right)$.This served as an input in Equation (7) for $K_{m}$ while the quartz particles were treated as rigid inclusions. Based on these guidelines, the drying shrinkage of a three-component composite, $S_{m+P+Q}$, was predicted as, 


$$
\frac{S_{m+P+Q}}{S_{m+P}}=1-\frac{\frac{2 E_{Q} \phi_{Q}}{1-2 v_{Q}}\left(1-\frac{S_{Q}}{S_{m+P}}\right)}{\frac{E_{Q}}{1-2 v_{Q}}+\frac{E_{m+P}}{1-2 v_{m+P}}+\left(\frac{E_{Q}}{1-2 v_{Q}}-\frac{E_{m+P}}{1-2 v_{m+P}}\right) \phi_{Q}}
$$

459

460

461

462

463

464

465

466

467

468

469

470

471

where $S_{m+p}$ was obtained as a function of $S_{m}$ by Equation (7).Figure 10 shows the measured and predicted shrinkage strains of PCM and/or quartz containing composites normalized by that of plain paste shrinkage, $S_{m}$, after 28 days of drying. It is noted that Hobbs model can accurately predict the shrinkage of composites containing both stiff, and/or compliant inclusions. The results indicate that, broadly, PCMs do not restrain paste shrinkage, and fulfill a role similar to air-voids (i.e., in the context of shrinkage) in the system. This is significant as while PCM microcapsules do not reduce shrinkage, in spite of the effects of dilution (i.e., a reduction in paste content), when dosed with quartz inclusions, the latter serve as a shrinkage restraining agent. Nevertheless, since PCMs are expected to be dosed as replacement of fine mineral aggregates, the overall shrinkage that develops can be adjusted by the dosage of stiff inclusions present in the mixture.

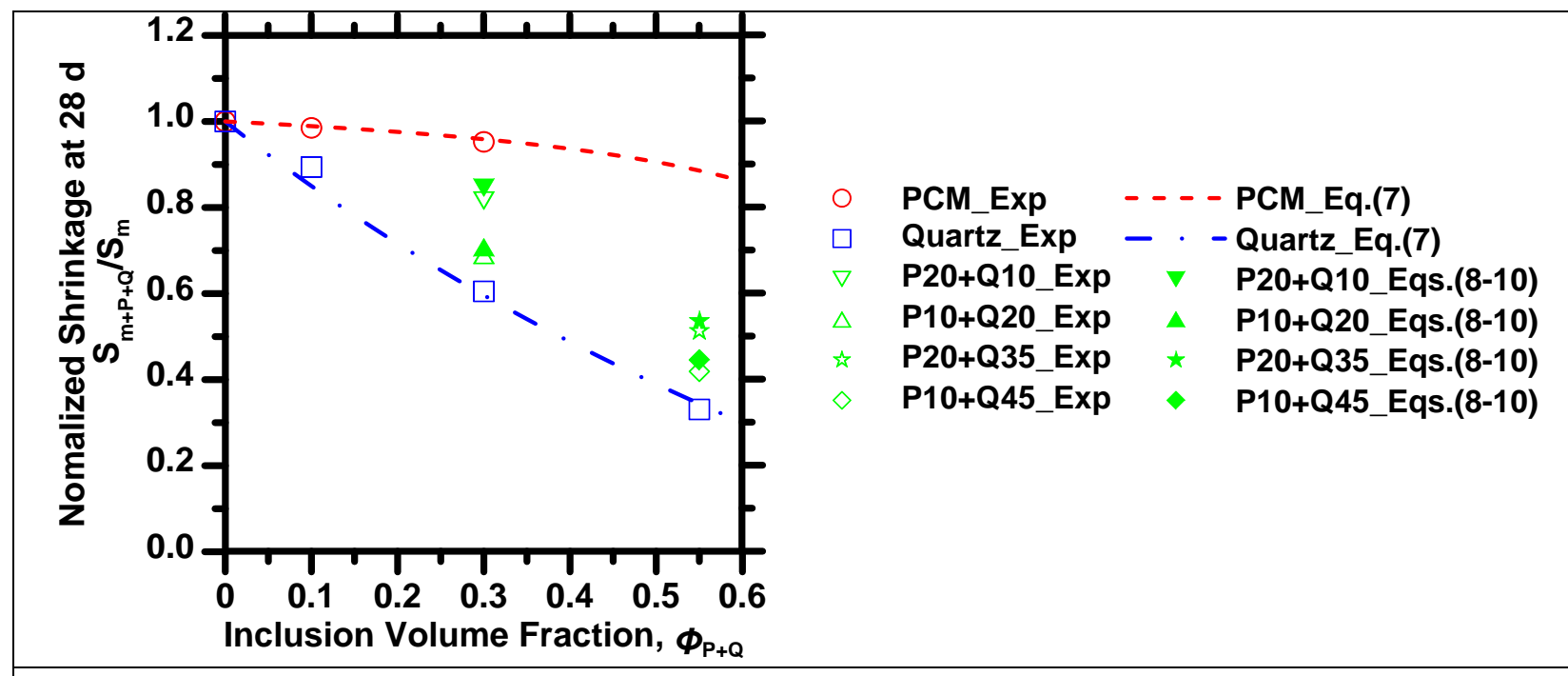

Figure 10: A comparison of measured and modeled drying shrinkage data of all cementitious mixtures after 28 days of drying, normalized by shrinkage of plain paste with $w / c=0.45$.

472

473

474

475

476

477

478

479

480
It is worth pointing out that in practical applications the effect of temperature cycling on the expansion and shrinkage of the PCM capsules may be relevant. While it is well known that thermal expansion and shrinkage of the PCM's paraffin core is much higher than that of the MF shell, typically, the PCM capsules are only partially filled with core material toaccount for the thermal expansion mismatch of the core and shell components. In fact, other research carried out by the present authors has revealed that the effective coefficient of thermal expansion of the PCM microcapsules (core+shell) is similar to that of the encapsulation (shell) material [57]. Since the coefficient of thermal expansion of the shell is on the same order as that of the 
cement paste matrix, this ensures that no damage would occur at the interface between the cement paste and the microcapsules when temperature changes - more so since the shell is around an order of magnitude less stiff than the cement paste matrix. As such, the addition of microencapsulated PCMs is expected to exert no detrimental effect on volume changes of cementitious composites.

\section{Summary and conclusions}

This study has investigated how the dosage of microencapsulated PCMs influences the durability of cementitious materials. It is noted that, while PCMs remain unaffected in alkaline solutions, they experience a significant enthalpy reduction, on the order of $25 \%$, when exposed to sulfate-bearing environments.The mechanism of such enthalpy reduction was identified as hydrolysis of the melamine-formaldehyde PCM capsule followed by its reaction with sulfate ions to form a melamine-sulfate supramolecular crystal. These reactions result in shell rupture following which the paraffinic PCM core too contacts sulfate ions, resulting in enthalpy reduction. With regards to water sorption, PCMs serve as a non-sorptive inclusion similar to graded quartz sand. Therefore, increasing the volume fraction of either inclusion reduced the volume of water sorbed, and the rate of water sorption. These effects, especially the extent of terminal water sorption, can be estimated for the case of non-sorptive inclusions using Powers' model [49]. Furthermore, the drying shrinkage of cementitious composites was essentially unaltered by the presence of PCMs, as such compliant inclusions are unable to offer any resistance to the cement paste's shrinkage. On the other hand, stiff quartz inclusions reduced shrinkage significantly - due to the effects of aggregate restraint. The model of Hobbs is able to properly capture the effects of both, inclusion stiffness and volume fraction, providing a means to estimate the shrinkage of cementitious composites containing such inclusions. In general, it is noted that, while PCMs may themselves be detrimentally impacted in sulfate-containing cementitious environments, they do not in any way detrimentally impact the durability of cementitious composites in which they are embedded.

510 The authors acknowledge financial support for this research provisioned via an Infravation ERA511 NET Plus Grant (31109806.0001), the National Science Foundation (CMMI: 1130028, CAREER: 512 1253269) andCalifornia Energy Commission (Contract: PIR:12-032). The authors also kindly 513 acknowledge financial support provided by The Sustainable L.A. Grand Challenge and the Office 514 of the Vice-Chancellor for Research at UCLA. The contents of this paper reflect the views and 515 opinions of the authors, who are responsible for the accuracy of datasets presented herein. The 516 Laboratory for the Chemistry of Construction Materials $\left(\right.$ LC $\left.^{2}\right)$ and the Molecular Instrumentation Center at UCLAgratefully acknowledge the support that has made their operations possible.

\section{References}

[1] M. Isaac, D.P. van Vuuren, Modeling global residential sector energy demand for heating and air conditioning in the context of climate change, Energy Policy 37 (2009) 507-521.

[2] M.M. Farid, A.M. Khudhair, S.A.K. Razack, S. Al-Hallaj, A review on phase change energy storage: materials and applications, Energy Convers. Manage. 45 (2004) 1597-1615.

[3] A.M. Khudhair, M.M. Farid, A review on energy conservation in building applications with 
thermal storage by latent heat using phase change materials,Energy Convers. Manage. 45 (2004) 263-275.

[4] E. Oro, A. de Gracia, A. Castell, M.M. Farid, L.F. Cabeza, Review on phase change materials (PCMs) for cold thermal energy storage applications, Appl. Energy 99 (2012) 513-533.

[5] B. Zalba, J.M. Marin, L.F. Cabeza, H. Mehling, Review on thermal energy storage with phase change: materials, heat transfer analysis and applications, Appl. Therm. Eng. 23 (2003) 251-283.

[6] A. M. Thiele, Z. Wei, G. Falzone, B. A. Young, N. Neithalath, G. Sant, L. Pilon, Figure of merit for the thermal performance of cementitious composites containing phase change materials, Cem. Concr. Comp. 65 (2016) 214-226.

[7] D.W. Zhang, H. Furuuchi, A. Hori, T. Ueda, Fatigue degradation properties of PCM-concrete interface, J. Adv. Concr. Technol. 7 (2009) 425-438.

[8] J.-F. Su, X.-Y. Wang, H. Dong, Micromechanical properties of melamine-formaldehyde microcapsules by nanoindentation: effect of size and shell thickness, Mater. Lett. 89 (2012) 1-4.

[9] W. Li, G. Song, G. Tang, X. Chu, S. Ma, C. Liu, Morphology, structure and thermal stability of microencapsulated phase change material with copolymer shell, Energy 36 (2011) 785791..

[10] M. Aguayo, S. Das, A. Maroli, N. Kabay, J.C.E. Mertens, S.D. Rajan, G. Sant, N. Chawla, N. Neithalath, The influence of microencapsulated phase change material (PCM) characteristics on the microstructure and strength of cementitious composites: experiments and finite element simulations, Cem. Concr. Comp. 73 (2016) 29-41.

[11] J. Chen, F.J. Liu, Y.F. Zheng, Review on phase change material slurries, Adv. Mater. Res. 860863 (2014) 946-951.

[12] F. Fernandes, S. Manari, M. Aguayo, K. Santos, T. Oey, Z. Wei, G. Falzone, N. Neithalath, G. Sant, On the feasibility of using phase change materials (PCMs) to mitigate thermal cracking in cementitious materials, Cem. Concr. Comp. 51 (2014) 14-26.

[13] P. Meshgin, Y. Xi, Y. Li, Utilization of phase change materials and rubber particles to improve thermal and mechanical properties of mortar, Constr. Build. Mater. 28 (2012) 713-721.

[14] M. Hunger, A.G. Entrop, I. Mandilaras, H.J.H. Brouwers, M. Founti, The behavior of selfcompacting concrete containing micro-encapsulated phase change materials, Cem. Concr. Res. 31 (2009) 731-743.

[15] A. Sari. Thermal reliability test of some fatty acids as PCMs used for solar thermal latent heat storage applications. Energy Convers. Manage. 44 (2003) 2277-2287.

[16] J. Skalny, I. Jawed, H.F.W. Taylor, Studies on hydration of cement: recent developments, World Cem. Technol. 8 (1978) 183-186.

[17] G.C. Bye, Portland Cement: Composition, Production and Properties, Thomas Telford Publishing, London, 1999.

[18] J.W. Bullard, H.M. Jennings, R.A. Livingston, A. Nonat, G.W. Scherer, J.S. Schweitzer, K.L. Scrivener, J.J. Thomas, Mechanisms of cement hydration, Cem. Concr. Res. 41 (2011) 1208-1223.

[19] D.E. Macphee, E.E. Lachowski, A.H. Taylor, T.J. Brown, Microstructural development in pore reduced cement (PRC), in: MRS Proceedings, 245 (1991) 303-308. 
[20] S.C. Taylor, W.D. Hoff, M.A. Wilson, K.M. Green, Anomalous water transport properties of Portland and blended cement-based materials, J. Mater. Sci. Lett. 18 (1999) 1925-1927.

[21] D.R.M. Brew, F.C. de Beer, M.J. Radebe, R. Nshimirimana, P.J. McGlinn, L.P. Aldridge, T.E. Payne, Water transport through cement-based barriers-A preliminary study using neutron radiography and tomography, Nucl. Instrum. Methods Phys Res. A 605 (2009) 163-166.

[22] R. Henkensiefken, J. Castro, D. Bentz, T. Nantung, J. Weiss, Water absorption in internally cured mortar made with water-filled lightweight aggregate, Cem. Concr. Res. 39 (2009) 883-892.

[23] J. Castro, D. Bentz, J. Weiss, Effect of sample conditioning on the water absorption of concrete, Cem. Concr. Comp. 33 (2011) 805-813.

[24] C. Hall, W.D. Hoff, S.C. Taylor, M.A. Wilson, B.G. Yoon, H.W. Reinhardt, M. Sosoro, P. Meredith, A.M. Donald, Water anomaly in capillary liquid absorption by cement-based materials, J. Mater. Sci. Lett. 14 (1995) 1178-1181.

[25] L.C. Wang, Analytical methods for prediction of water absorption in cement-based material, China Ocean Eng. 23 (2009) 719-728.

[26] A.L. Stockett, A.M. Schneide, F.J. Mardulie, An analysis of drying shrinkage data for Portland cement mortar and concrete, J. Mater. 2 (1967) 829-842.

[27] J. Bisschop, J.G.M. van Mier, Effect of aggregates on drying shrinkage microcracking in cement-based composites, Mater. Struct. 35 (2002) 453-461.

[28] S.D. Abyaneh, H.S. Wong, N.R. Buenfeld, Computational investigation of capillary absorption in concrete using a three-dimensional mesoscale approach, Comput. Mater. Sci. 87 (2014) 54-64.

[29] D.W. Hobbs, The dependence of the bulk modulus, Young's modulus, creep, shrinkage, and thermal expansion of concrete upon aggregate volume concentration, Mater. Struct. 4 (1971) 107-114.

[30] A.R. Sakulich, D.P. Bentz, Increasing the service life of bridge decks by incorporating phasechange materials to reduce freeze-thaw cycles, J. Mater. Civ. Eng. 24 (2012) 1034-1042.

[31] ASTM International, ASTM Standard C150/C150M: Standard specification for Portland cement, West Conshohocken, PA, 2016.

[32] ASTM International, ASTM Standard C192/C192M: Standard practice for making and curing concrete test specimens in the laboratory, West Conshohocken, PA, 2012.

[33] ASTM International, ASTM Standard C778: Standard specification for standard sand, West Conshohocken, PA, 2013.

[34] C.F. Ferraris, V.A. Hackley, A.I. Avilés, Measurement of particle size distribution in portland cement powder: Analysis of ASTM round robin studies, Cem. Concr. and Aggreg. 26 (2004) 1-11.

[35] G. Gao, S. Moya, H. Lichtenfeld, A. Casoli, H. Fiedler, E. Donath, H. Mohwald, The decomposition process of melamine formaldehyde cores: the key step in the fabrication of ultrathin polyelectrolyte multilayer capsules, Macromol.Mater. Eng. 286 (2001) 355361.

[36] G. Ghosh, Dispersion-equation coefficients for the refractive index and birefringence of calcite and quartz crystals, Opt. Commun. 163 (1999) 95-102.

[37] ASTM International, ASTM Standard E1269: Standard test method for determining specific 
heat capacity by differential scanning calorimetry, West Conshohocken, PA, 2011.

[38] ASTM International, ASTM Standard C1585: Standard test method for measurement of rate of absorption of water by hydraulic-cement concretes, West Conshohocken, PA, 2012.

[39] ASTM International, ASTM Standard C157: Standard test method for length change of hardened hydraulic-cement mortar and concrete, West Conshohocken, PA, 2014.

[40] N. Ukrainczyk, S. Kurajica, J. Sipusic, Thermophysical comparison of five commercial paraffin waxes as latent heat storage materials, Chem. Biochem. Eng. Q. 24 (2010) 129-137.

[41] ASTM International, ASTM Standard C305: Standard practice for mechanical mixing of hydraulic cement pastes and mortars of plastic consistency, West Conshohocken, PA, 2014.

[42] S. Mindess, J.F. Young, D. Darwin. Concrete, second ed., Prentice Hall, New Jersey, 2003.

[43] D.R. Bauer, Melamine Formaldehyde cross-linker: characterization, network formation and cross-link degradation, Prog. Org. Coat. 14 (1986) 193-218.

[44] X.H. Li, S.Z. Yang, W.D. Xiang, Q. Shi, A novel porous supramolecular complex constructed by the co-crystallization of melamine and sulfate via hydrogen bonds and aromatic pi-pi interaction, Struct. Chem. 18 (2007) 661-666.

[45] C. Hall, Water sorptivity of mortars and concretes: A review, Mag. Concr. Res. 41 (1989) 5161.

[46] Y. Xi, Z.P. Bažant, L. Molina, H.M. Jennings, Moisture diffusion in cementitious materials Moisture capacity and diffusivity, Adv. Cem. Based Mater. 1 (1994) 258-266.

[47] N. Neithalath, Analysis of moisture transport in mortars and concrete using sorptiondiffusion approach, ACI Mater. J. 103 (2006) 209-217.

[48] C. Hall, W.D. Hoff, M.A. Wilson, Effect of nonsorptive inclusions on capillary absorption by a porous material, J. Phys. D: Appl. Phys. 26 (1993) 31-34.

[49] T.C. Powers, T.L. Brownyard, Studies of the physical properties of hardened portland cement paste, J. Am. Concr. Inst. Proc. 43 (1947) 469-504.

[50] O.M. Jensen, P.F. Hansen, Water-entrained cement-based materials I: principle and theoretical background, Cem. Concr. Res. 31 (2001) 647-654.

[51] J.F. Young, S. Mindess, A. Bentur, R. Gray, The Science and Technology of Civil Engineering Materials, Prentice Hall, New Jersey, 1998.

[52] G. Falzone, G. Puerta Falla, Z. Wei, M. Zhao, A. Kumar, M. Bauchy, N. Neithalath, L. Pilon, G. Sant, The influences of soft and stiff inclusions on the mechanical properties of cementitious composites, Cem. Concr. Comp. 71 (2016) 153-165.

[53] G. De Schutter, L. Taerwe, Degree of hydration-based description of mechanical properties of early age concrete, Mater. Struct. 29 (1996) 335-344.

[54] M. Hossain, C. Ketata, Experimental study of physical and mechanical properties of natural and synthetic waxes using uniaxial compressive strength test, in: Proceedings of Third International Conference on Modeling, Simulations and Applied Optimalization, 2009, pp. $1-5$.

[55] X.Q. Chen, S.L. Zhang, G.J. Wagner, W.Q. Ding, R.S. Ruoff, Mechanical resonance of quartz microfibers and boundary condition effects, J. Appl. Phys. 95 (2004) 4823-4828.

[56] R. Hill, The elastic behaviour of a crystalline aggregate, Proc. Phys. Soc. Sect. A 65 (1952) 349-354.

[57] B.A. Young, Z. Wei, J. Rubalcava-Cruz, G. Falzone, A. Kumar, N. Neithalath, G. Sant, L. Pilon, 
657

658

659

A general method forretrieving the thermal deformation properties of core-shell inclusions embedded in a continuous matrix, Mater. Des. (under review). 